\title{
Mutations Affecting the Sulphur Assimilation Pathway in Aspergillus nidulans: Their Effect on Sulphur Amino Acid Metabolism
}

\author{
By ANDRZEJ PASZEWSKI*, WIESŁAWA PRAŻMO, JANINA \\ NADOLSKA AND MICHAL REGULSKI \\ Institute of Biochemistry and Biophysics, Polish Academy of Sciences, Ul. Rakowiecka 36, \\ 02-532 Warszawa, Poland
}

(Received 14 September 1983; revised 3 November 1983)

\begin{abstract}
Several sul-reg mutants of Aspergillus nidulans isolated as constitutive for arylsulphatase were studied with respect to the regulation of enzymes involved in cysteine and homocysteine synthesis and to the pool of sulphur amino acids. All mutants examined showed a decreased concentration of glutathione as compared with the wild type, and all mutants, with one exception, had a decreased total pool of sulphur amino acids. The results suggest that the mutants are leaky in the sulphate assimilation pathway. They show derepression of cysteine synthase, homocysteine synthase, cystathionine $\beta$-synthase and $\gamma$-cystathionase. In spite of having derepressed homocysteine synthase, the enzyme which constitutes an alternative pathway for homocysteine synthesis, the sul-reg mutations do not suppress lesions in genes required for the main homocysteine-synthesizing pathway. This indicates that the derepression of homocysteine synthase is not in itself sufficient for physiological functioning of this enzyme, but seems to depend also on the effectiveness of cysteine synthesis and sulphide formation.
\end{abstract}

\section{INTRODUCTION}

There are two pathways for the synthesis of homocysteine and cysteine in fungi (Fig. 1). It has been shown in Aspergillus nidulans that the pathway involving direct synthesis of homocysteine from $O$-acetylhomoserine and sulphide operates only when the main pathway of cysteine synthesis (cysteine synthase, Fig. 1, step 1) is impaired by mutation (Paszewski \& Grabski, 1975). In fact, mutants blocked in step (1) show derepression of enzymes of the sulphur assimilation pathway as well as of the three enzymes constituting an alternative pathway (homocysteine synthase, cystathionine $\beta$-synthase and $\gamma$-cystathionase; Fig. 1, steps 4,5 and 6 , respectively). It was also found that these mutations are pathway suppressors of the 'cystathionine' pathway (cystathionine $\gamma$-synthase and $\beta$-cystathionase; Fig. 1, steps 2 and 3, respectively) due to the direct synthesis of homocysteine, which serves as a precursor of both cysteine and methionine. We have also found that the mutants $c y s B$ and $c y s C$ show a derepression of arylsulphatase activity. This focused our attention on the arylsulphatase constitutive mutants sul-reg, previously isolated and characterized by Siddiqui and his co-workers (Siddiqui et al., 1966; Apte et al., 1974; N. K. Singh, personal communication). It was of interest to know if the regulation of other sulphur-related enzymes is also altered, and whether or not these mutations can suppress meth $A$, meth $B$ and meth $G$ mutations.

Here we report that most, but not all, sul-reg mutations are leaky in their sulphate assimilation. They can grow in normal minimal medium, but the mutations cause a permanent sulphur limitation which, in turn, produces changes in the pool of sulphur amino acids as well as enzyme regulation. In fact, these mutants provide a very useful model to study the effects of sulphur limitation without altering the growth medium. 


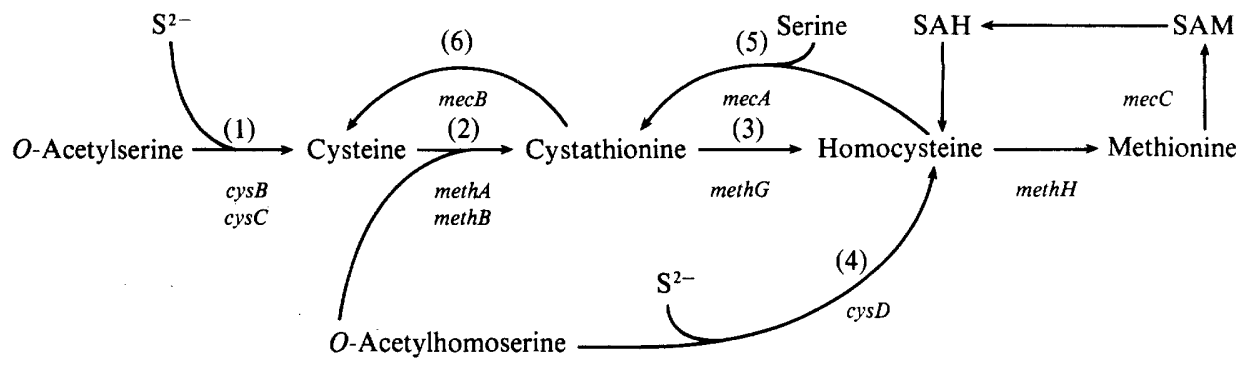

$$
\mathrm{SO}_{4}^{2-} \stackrel{\mathrm{H}}{\longrightarrow} \mathrm{SO}_{4}^{2-} \stackrel{(7)}{\longrightarrow} \mathrm{APS} \longrightarrow \mathrm{PAPS} \longrightarrow \mathrm{SO}_{3}^{2-} \stackrel{(8)}{\longrightarrow} \mathrm{S}^{2-}
$$

Fig. 1. An outline of sulphur amino acid metabolism in Aspergillus nidulans. Enzymes: (1) cysteine synthase, (2) cystathionine $\gamma$-synthase, (3) $\beta$-cystathionase, (4) homocysteine synthase, (5) cystathionine $\beta$-synthase, (6) $\gamma$-cystathionase, (7) ATP sulphurylase, (8) sulphite reductase. SAM, $S$-adenosylmethionine; SAH, $S$-adenosylhomocysteine; PAPS, adenosine 3'-phosphate 5'-phosphosulphate; APS, adenosine 5'-phosphosulphate.

\section{METHODS}

Strains. The following strains of $A$. nidulans were kindly provided by $\operatorname{Dr}$ N. K. Singh (Tate Institute of Fundamental Research, Bombay, India): sul-regAl(nicB8 riboB2), sul-regB2(lysB5 nicB8), sul-regC7(pyroA4), sulregD11(lysB5 nicB8) and sul-regE14(lysB5). Strains mecB10 anAl phenA2 biAl, blocked in $\gamma$-cystathionase (Pieniążek et al., 1973a) and mecC13(anAl biAl), deficient in $S$-adenosylmethionine synthetase (Pieniążek et al., $1973 b$ ), were obtained from the collection of the Department of Genetics, University of Warsaw. The strain cysD1, impaired in homocysteine synthase, was described previously (Paszewski \& Grabski, 1975). The wild type used as reference strain in the experiments was pyro $4 \mathrm{AAl}$.

Media, culture conditions and extract preparation. Liquid minimal medium described previously (Paszewski \& Grabski, 1974), was supplemented with sulphur amino acids as indicated. Cultures were started by inoculation of $100 \mathrm{ml}$ medium in $300 \mathrm{ml}$ Erlenmeyer flasks with 3-5 ml of a heavy conidial suspension, and grown in a rotary shaker (150 r.p.m.) at $30^{\circ} \mathrm{C}$ for $16-18 \mathrm{~h}$. Mycelia were collected on surgical gauze, washed three times with distilled water and blotted on filter paper. For enzyme assays, extracts were prepared from mycelial pads as described previously (Paszewski \& Grabski, 1973) with the use of $0.1 \mathrm{M}$-Tris/ $\mathrm{HCl}$ buffer, $\mathrm{pH} 8 \cdot 0$, in the case of ATP-sulphurylase and arylsulphatase determination, and $0.1 \mathrm{~m}$-potassium phosphate buffer, $\mathrm{pH} 7.5$, for the remaining enzymes.

Enzyme assays. $\beta$-Cystathionase (EC 4.4.1.8) and $\gamma$-cystathionase (EC 4.4.1.1) were assayed as described by Paszewski \& Grabski (1974). Homocysteine synthase (EC 4.2.99.10) was assayed in the reaction mixture described previously (Paszewski \& Grabski, 1973); the homocysteine formed was determined by the method of Kredich \& Tomkins (1966). Cysteine synthase (EC 4.2.99.8) and cystathionine $\beta$-synthase (EC 4.2.1.22) were assayed according to Pieniążek et al. (1973) and ATP-sulphurylase (EC 2.7.7.4) and sulphite reductase (EC 1.8.1.2) were assayed by the methods of de Vito \& Dreyfuss (1964). The sulphide formed was determined according to Siegel (1965). Arylsulphatase (EC 3.1.6.1) was assayed according to Metzenberg \& Parson (1966), calculating the activity with the use of a molar extinction coefficient of 12000 for $p$-nitrophenol (Razzell, 1963).

Protein determination. Protein was estimated by the method of Lowry or by the method of Bradford (1976).

DEAE-cellulose chromatography. Cellular extract for this purpose was prepared in $0.05 \mathrm{M}$-Tris $/ \mathrm{HCl}$ buffer, $\mathrm{pH} 7.8$, containing $40 \mathrm{M}$-pyridoxal 5 '-phosphate and $1 \mathrm{mM}$-EDTA. Homogenates were centrifuged at $15000 \mathrm{~g}$ for $10 \mathrm{~min}$ and subsequently at $100000 \mathrm{~g}$ for $1 \mathrm{~h}$. The supernatant was diluted with extraction buffer to a protein concentration of $1 \mathrm{mg} \mathrm{ml}^{-1} ; 40 \mathrm{ml}$ of such an extract was applied onto the DEAE-cellulose column $(1.0 \times 15 \mathrm{~cm})$ equilibrated with the same buffer at a flow rate of $20 \mathrm{ml} \mathrm{h}^{-1}$. The column was washed with $40 \mathrm{ml}$ of the extraction buffer and subsequently with $300 \mathrm{ml}$ of a linear salt gradient, 0.0 to $0.3 \mathrm{M}-\mathrm{NaCl}$ in the same buffer. The flow rate was adjusted to $10 \mathrm{ml} \mathrm{h}^{-1}$. Fractions of $3 \mathrm{ml}$ were collected and 0.05 or $0.1 \mathrm{ml}$ samples were taken for determination of enzyme activity.

Polyacrylamide gel electrophoresis. Protein separation was carried out according to Laemmli (1970) with the use of Bethesda Research Laboratories preparative gel electrophoresis system (BRL no. 1110PG). Details are given in the legend to Fig. 3.

Determination of pools of ${ }^{35} S$-labelled amino acids. The strains were grown in minimal medium supplemented with $\mathrm{Na}_{2}{ }^{35} \mathrm{SO}_{4}\left(4.8 \times 10^{9}\right.$ c.p.m. mmol $\left.{ }^{-1}\right)$ for $18 \mathrm{~h}$ in standard conditions. The mycelia were harvested and ${ }^{35} \mathrm{~S}$ - 
labelled amino acids were isolated and separated by thin-layer chromatography on cellulose, as described previously (Paszewski \& Grabski, 1974). The position of the radioactive spots was determined by autoradiography. The main band (about $90 \%$ of the radioactivity), containing poorly separated glutathione, cystathionine, cystine, homocystine and mixed disulphides, was scraped off the plates. The amino acids were eluted from the cellulose with $0 \cdot 1 \mathrm{M}-\mathrm{HCl}$. The eluate was evaporated and the residue oxidized with a mixture of $\mathrm{H}_{2} \mathrm{O}_{2}$ and formic acid, followed by separation of its contents by high-voltage electrophoresis, as described by Bessman et al. (1967), together with internal standards of identically oxidized L-cysteine, DL-homocysteine, L-glutathione and Lcystathionine. The positions of particular amino acids were determined by staining with ninhydrin. The spots were cut out and the radioactivity counted in a PPO/POPOP scintillation mixture. ${ }^{35} \mathrm{~S}$-Methionine and ${ }^{35} \mathrm{~S}$ hypotaurine were estimated directly by scraping their respective spots from the chromatogram and counting the radioactivity.

Genetic techniques. Crossing methods and nutritional tests were as described by Pontecorvo et al. (1953). For screening colonies with constitutive arylsulphatase activity, the plates were flooded with 30 mM-indoxyl sulphate in $50 \mathrm{~mm}$-Tris buffer, $\mathrm{pH} 8 \cdot 0$. Colonies with active enzyme turn blue.

Reagents. L-Cystathionine, L-cysteine, DL-homocysteine thiolactone $\mathrm{HCl}, \mathrm{L}$-serine, L-methionine and indoxyl sulphate were obtained from Sigma. Pyridoxal 5'-phosphate was a product of Merck. ${ }^{35}$ S-labelled sodium sulphate was obtained from the Institute of Nuclear Research, Swierk, Poland. $O$-Acetyl-L-serine and $O$-acetyl-L-homoserine were synthesized according to Wiebers \& Garner (1967). DEAE-cellulose, type DE52, was obtained from Whatman. $N, N^{\prime}$-methylenebisacrylamide and sodium dodecyl sulphate were from $\mathrm{BDH}$ and acrylamide from Merck. All inorganic chemicals were of reagent grade.

\section{RESULTS}

\section{Levels of sulphur metabolizing enzymes in the wild type and sul-reg strains}

The results presented in Table 1 indicate that sul-reg mutants isolated as constitutive for arylsulphatase show elevated levels of several enzymes of sulphur metabolism. ATP sulphurylase and sulphite reductase exhibit a similar degree of derepression to that observed in the cys $B 1$ and cysCl mutants, apparently impaired in the last step of cysteine synthesis (Paszewski \& Grabski, 1975). There are two exceptions: sul-regD11 has a low activity of ATP sulphurylase and it may be a leaky mutation in the structural gene coding this enzyme; sul-regB2 shows a decreased level of sulphite reductase. The levels of these two enzymes are only slightly lower than those observed in the wild type, but it is very likely that the mutants produce more of the respective enzymes but with lower specific activities. Therefore, the levels of these two enzymes should be compared with those observed in other sul-reg mutants rather than with the wild type. Additionally, the sulregB2 strain, unlike sul-regD1, shows a decreased level of $\beta$-cystathionase. The three enzymes constituting the alternative pathway of homocysteine and cysteine synthesis, i.e. homocysteine synthase, cystathionine $\beta$-synthase and $\gamma$-cystathionase, show a similar degree of derepression as observed previously in the $c y s B 1$ and cysCI mutants. The activity of cysteine synthase is 2 to $3-$ fold higher in the sul-reg strains as compared with the wild type. It was observed in Saccharomyces cerevisiae (Yamagata et al., 1976), Cephalosporium acremonium (Dobeli \& Nuesch, 1980) and Saccharomycopsis lipolytica (Morzycka \& Paszewski, 1982) that homocysteine synthase also exhibits cysteine synthase activity. If this is also the case for A. nidulans, the elevated level of cysteine synthase activity in sul-reg strains could be attributed to homocysteine synthase. To check this, the cysD1 mutation (impaired homocysteine synthase) was introduced into the sul-regD11 strain. As shown in Table 2, the double mutant sul-regDI1 cysDI exhibits about a 3-fold decrease of cysteine synthase activity and about a 12-fold decrease of homocysteine synthase activity, as compared with the sul-regD11 mutant. Data presented in Fig. 2 clearly indicate that there are two enzyme fractions with cysteine synthase activity, one of which also exhibits homocysteine synthase activity. The fact that the second cysteine synthase peak and the homocysteine synthase peak both disappeared in the extract of the double mutant suggests the presence of a bifunctional (at least in vitro) enzyme which is derepressed in sul-reg strains and impaired in strains carrying the cysDl mutation. (We were able to detect some activity of the bifunctional enzyme in the double mutant by washing the DEAE-cellulose column with $0.07 \mathrm{M}-\mathrm{NaCl}$.) The two activities co-migrate on polyacrylamide gel electrophoresis (Fig. 3), supporting the hypothesis that a single enzyme is involved. The cysDl mutation does not affect the regulation of other enzymes which are derepressed in sul-reg strains. As shown in 

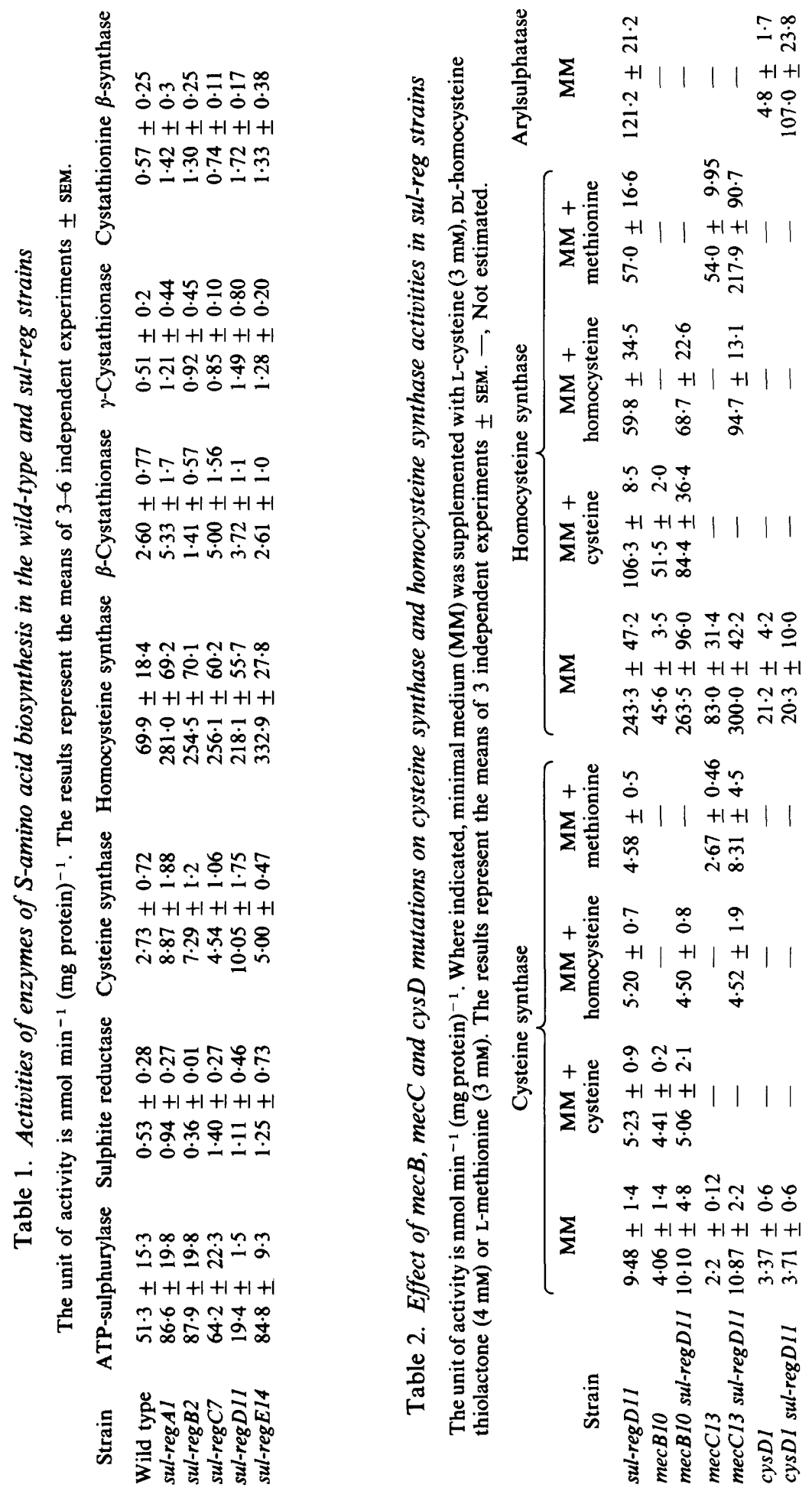


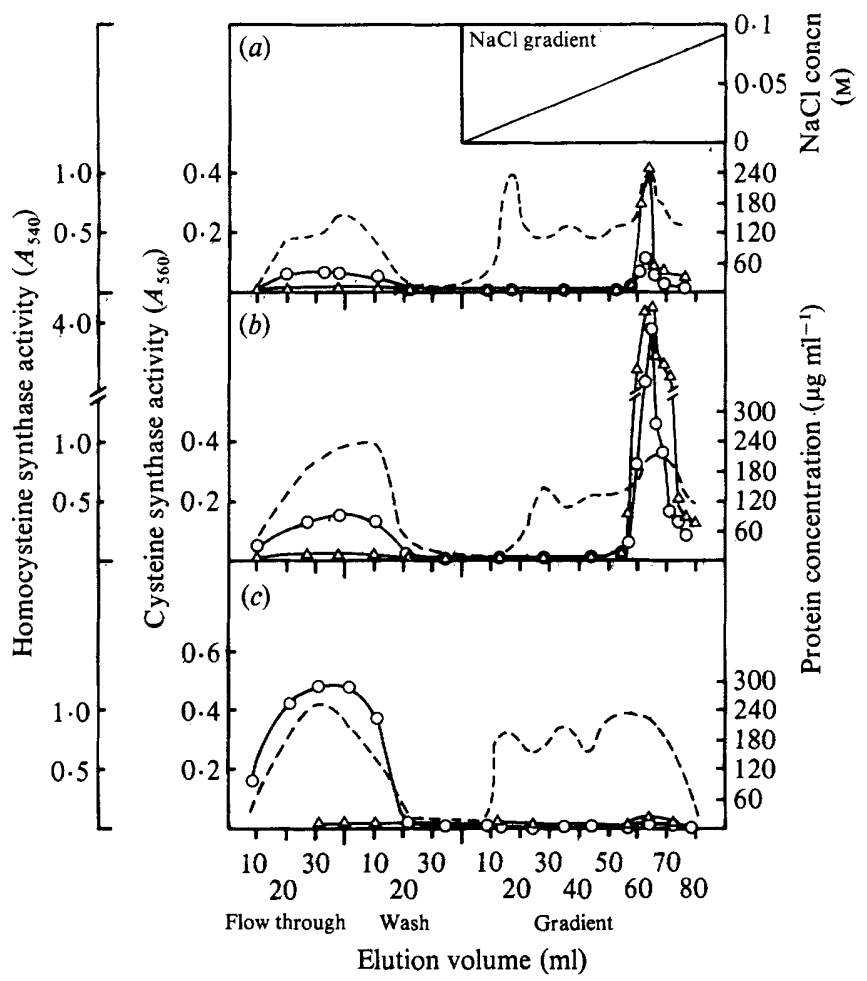

Fig. 2. DEAE-cellulose elution profile of cysteine synthase and homocysteine synthase from $A$. nidulans. Monofunctional cysteine synthase elutes in the flow-through and bifunctional cysteine-homocysteine synthase elutes with about $0.07 \mathrm{M}-\mathrm{NaCl}$. $\bigcirc$, Cysteine synthase; $\Delta$, homocysteine synthase; -.--, protein. (a) Wild type, (b) sul-reg $D_{5},($ c $)$ cys DI sul-reg $D 11_{5}$. The results are from a single representative experiment.

Table 2, the double mutant sul-regD11 cysDI has a high level of arylsulphatase, corresponding to that of the single sul-reg mutant. It is likely, therefore, that cys $D 1$ is a structural locus coding for the bifunctional enzyme.

Cysteine synthase in the sul-reg mutants is repressible under conditions of homocysteine synthase repression. As shown in Table 2, methionine, homocysteine and cysteine cause repression of both synthases when supplemented in the growth medium. The fact that repression of homocysteine synthase is stronger than that of cysteine synthase suggests that it is mainly, if not only, the bifunctional enzyme which is repressed. Cysteine synthase and homocysteine synthase were also found to be repressible in the remaining four sul-reg mutants. It seems that the enzyme derepression observed in these strains is unlikely to result from a mutation in regulatory genes, but rather is due to an alteration in the pool of sulphur amino acids. The mecC13 mutation (a partial loss of $S$-adenosylmethionine synthetase) protects the enzymes against repression by methionine but not by homocysteine, indicating that methionine must be metabolized to homocysteine to cause enzyme repression. The latter compound causes repression even under conditions when mecBl mutation (a lesion in $\gamma$-cystathionase) prevents its conversion to cysteine.

In extracts of the sul-regDII cysDI strain we observed a higher level of monofunctional cysteine synthase than in the wild type. This may explain the fact that the total activity of the cysteine synthase in the double mutant is not lower than in the wild type, despite the drastic reduction of bifunctional enzyme activity. It is possible that there is some regulatory relationship between these two enzymes, but this problem requires further investigation. 


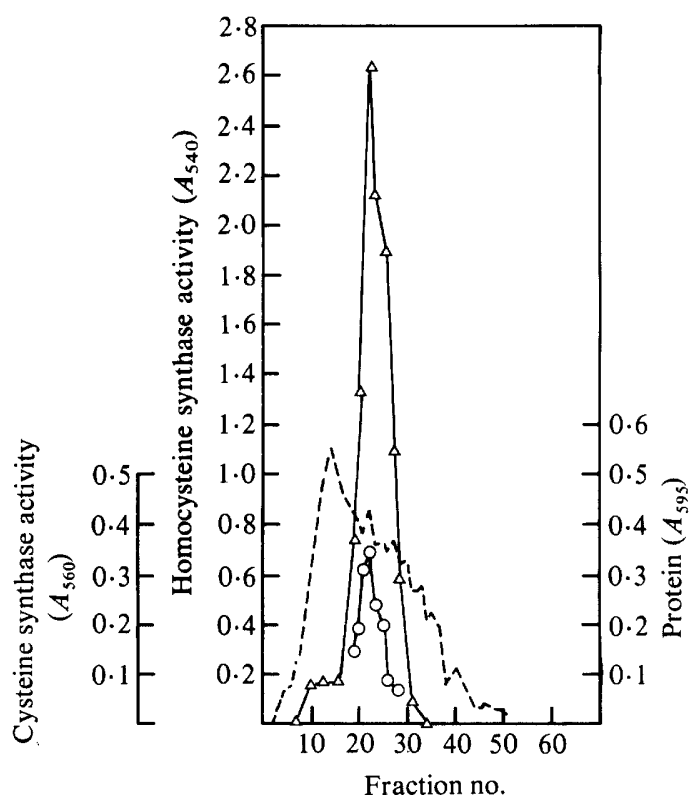

Fig. 3. Polyacrylamide gel electrophoresis of homocysteine synthase from A. nidulans. A sample (1 ml) containing $3.5 \mathrm{mg}$ protein from the peak fractions of homocysteine synthase activity from the DEAEcellulose column was applied to a $10 \%(\mathrm{w} / \mathrm{v})$ separating gel $(1 \mathrm{~cm}$ diameter, $4.5 \mathrm{~cm}$ height $)$. Electrophoresis was started with $2 \mathrm{~mA}$ current followed by $6 \mathrm{~mA}$ after the whole sample had entered the gel. Outcoming proteins were eluted continuously with the electrode buffer at the rate of $12 \mathrm{ml} \mathrm{h}^{-1}$. Fractions $(0.9 \mathrm{ml})$ were collected; 0.05 or $0.1 \mathrm{ml}$ of each fraction was withdrawn for enzyme determination. $\triangle$, Homocysteine synthase; $\bigcirc$, cysteine synthase; $\cdots$, protein.

Table 3. Accumulation of ${ }^{35}$ S-labelled amino acids in mycelia of the wild type and sul-reg mutants grown in the presence of ${ }^{35} \mathrm{SO}_{4}^{2-}$

Mycelia were grown in minimal medium containing ${ }^{35} \mathrm{SO}_{4}^{2-}\left(4.5 \times 10^{8}\right.$ c.p.m. mmol $\left.{ }^{-1}\right)$ for $18 \mathrm{~h}$ at $30^{\circ} \mathrm{C}$. The data are from a single experiment. Similar ratios were obtained in three analogous experiments. The results are expressed as $10^{-5} \times$ c.p.m. per g dry wt.

\begin{tabular}{lcccccc}
\multicolumn{1}{c}{ Strain } & Cysteine* & Homocysteine & Glutathione* & Cystathionine $\dagger$ & Methionine & Total $\neq$ \\
Wild type & $20 \cdot 4$ & $16 \cdot 5$ & $206 \cdot 2$ & $38 \cdot 3$ & $33 \cdot 7$ & $352 \cdot 6$ \\
sul-regA1 & $13 \cdot 3$ & $10 \cdot 2$ & $150 \cdot 1$ & $48 \cdot 2$ & $48 \cdot 8$ & $424 \cdot 0$ \\
sul-regB2 & $12 \cdot 7$ & $10 \cdot 3$ & 54.9 & $35 \cdot 9$ & $21 \cdot 1$ & $209 \cdot 4$ \\
sul-regC7 & $12 \cdot 1$ & $13 \cdot 5$ & $85 \cdot 6$ & $30 \cdot 2$ & $34 \cdot 8$ & $234 \cdot 1$ \\
sul-regDI1 & $7 \cdot 2$ & $5 \cdot 3$ & $114 \cdot 8$ & $40 \cdot 3$ & $39 \cdot 3$ & $304 \cdot 3$ \\
sul-regE14 & $12 \cdot 8$ & $9 \cdot 3$ & $64 \cdot 6$ & $56 \cdot 2$ & $31 \cdot 9$ & $220 \cdot 7$
\end{tabular}

* Estimated as sulphonic acids. (It was not estimated what fraction of these amino acids was originally in the thio- and what fraction was in the disulphide form.)

$\dagger$ Estimated as cystathionine sulphone.

$\ddagger$ Total ${ }^{35} \mathrm{~S}$ retained on Dowex $50\left(\mathrm{H}^{+}\right)$.

The pools of sulphur amino acids in the sul-reg mutants differ from those found in the wild type

The pools were studied by growing the strains in the presence of $\mathrm{Na}_{2}{ }^{35} \mathrm{SO}_{4}$ and measuring the radioactivity of several sulphur amino acids found in the water extracts from mycelia. The results of a representative experiment are given in Table 3 . While the differences in the ratio of cysteine and homocysteine between the mutants and the wild type were not always significant, the differences in glutathione and the total amount of ${ }^{35} \mathrm{~S}$ were very reproducible. Even the sulregAl strain which shows an increased total ${ }^{35} \mathrm{~S}$ pool has less glutathione compared to the wild type. The remaining sul-reg strains contain less sulphur in the pool; this is probably the result of some restrictions in the sulphate assimilation pathway. Enzyme lesions in this pathway were 
Table 4. Results of crosses between the cysB1, methB3 strain and various sul-reg strains

$\begin{array}{ccccc}\text { Cross } & \begin{array}{c}\text { No. of } \\ \text { progeny } \\ \text { tested }\end{array} & \overbrace{\text { Total }} & \text { With sul-reg mutation } & \text { Without sul-reg mutation } \\ \text { cysBl methB3 } & 130 & 37 & 21 & 16 \\ \times \text { sul-regA1 } & 148 & 30 & 15 & 15 \\ \times \text { sul-regB2 } & 126 & 35 & 22 & 13 \\ \times \text { sul-regC7 } & 150 & 38 & 17 & 21 \\ \times \text { sul-regD11 } & 149 & 31 & 16 & 15 \\ \times \text { sul-regE14 } & & & & \\ \end{array}$

found in the sul-regB2 and sul-regD11 strains but not all enzyme activities in this pathway were assayed, so it is possible that the remaining mutants are impaired in other steps.

\section{sul-reg mutations do not suppress lesions in the cysteine to homocysteine pathway}

Strain cysBI methB3 (cysB1 suppresses the methB3 lesion) was crossed with all sul-reg strains to determine whether these mutations suppress the meth $B 3$ mutation, and if so, whether they are allelic with $c y s B$. The results, shown in Table 4, indicate that the answer to both questions is negative, i.e. in all crosses about one quarter of progeny required methionine for growth, and about one half of $\mathrm{Meth}^{-}$segregants contained the sul-reg marker. Similar results were obtained in crosses between sul-reg mutants and methG55 strain. The sul-reg mutations do not suppress the methB and meth $G$ lesions. It was pointless, therefore, to test the allelism of the sul-reg mutations used in this study with other methionine suppressors: cysA1, cysCl and suAmeth (Paszewski \& Grabski, 1975).

\section{DISCUSSION}

The results obtained in this study indicate that the derepression in sul-reg mutants of a number of enzymes involved in the synthesis of sulphur amino acids results from sulphur limitation caused by a partial impairment of the sulphate assimilation pathway. This conclusion is strongly supported by the fact that a number of other sul-reg mutants, allelic to those studied here, require a source of reduced sulphur for growth, or are stimulated by sulphite or methionine (Apte et al., 1974). Interestingly, some sul-reg mutants have been found to be allelic to mutants blocked in the sulphate assimilation pathway ( $s$ loci) described by Arst (1968) (N. K. Singh, personal communication). It is evident that the enzyme derepression correlates best with a diminution of the glutathione pool among the sulphur compounds examined. A similar situation was found in Saccharomycopsis lipolytica (Morzycka et al., 1976). It is possible that glutathione, in addition to cysteine, may act as a regulatory effector.

The physiological role of homocysteine synthase in $A$. nidulans is not clear. The enzyme is not essential for the wild type but is necessary for the cys $A, c y s B, c y s C$ mutants blocked in the main pathway of cysteine synthesis (Pieniążek et al., 1974; Paszewski \& Grabski, 1975), since double mutants cysAl cysDI, cysBl cysDI and cysCl cysDI are auxotrophic. When mycelia of these double mutants are transferred for several hours from a methionine-containing medium to a minimal medium with ${ }^{35} \mathrm{SO}_{4}^{2-}$ as the sole sulphur source, only traces of radioactive sulphur can be detected in the pool of amino acids.

We have demonstrated that homocysteine synthase is necessary for the recycling of the methylthio group of 5 -methylthioadenosine to methionine (Guranowski \& Paszewski, 1982), but again this recycling does not seem necessary for the growth of the normal strain. Also, the cysteine synthase activity of this enzyme observed in vitro does not seem to operate in vivo because the double mutants cysBI mecB10 or cysBI mecAl are auxotrophic (Paszewski \& Grabski, 1973). There is evidence suggesting that a corresponding bifunctional enzyme in Saccharomyces cerevisiae (Yamagata et al., 1975) and in Saccharomycopsis lipolytica (Morzycka \& Paszewski, 1982) expresses the two activities both in vitro and in vivo.

Our data indicate that the monofunctional cysteine synthase is also subject to regulation. Its 
activity is clearly elevated in the double mutant sul-regD11 cysDI, that is under conditions of sulphide limitation and impairment of the alternative pathway of cysteine synthesis.

The sul-reg mutations, in spite of causing a derepression of homocysteine synthase, similar to or even higher than that observed in $c y s B 1$ and $c y s C l$ mutants, do not suppress mutations in the meth $A$, meth $B$ and $m e t h G$ genes specifying the cysteine to homocysteine pathway (steps 2 and 3 , Fig. 1). Therefore, a derepression of homocysteine synthase is not sufficient for suppression. The cys $B I$ and $c y s C l$ mutants are blocked in the last step of cysteine synthesis, but not in the sulphur assimilation pathway. In these mutants this pathway is derepressed and thus provides more sulphide than in the wild type. Sulphide can be utilized for homocysteine synthesis in the reaction catalysed by homocysteine synthase. Additionally, a shortage of cysteine makes the second substrate, $O$-acetylhomoserine, which is normally utilized for cystathionine synthesis, available for direct formation of homocysteine. In the sul-reg mutants, sulphide may be a limiting substrate and predominantly used for cysteine synthesis. This is presumably the cause of the failure of sul-reg mutations to suppress lesions in meth mutants. Since this is true in the case of meth $B$ mutants blocked in cystathionine $\beta$-synthase, the availability of $O$-acetylhomoserine for homocysteine synthesis does not seem to be a crucial factor determining the suppression.

One might expect, therefore, that all mutants which are derepressed in the sulphate assimilation pathway, and thus able to produce more sulphide, should suppress methionine mutations, even without elevation of the homocysteine synthase level.

We wish to thank Dr N. K. Singh for sending us strains and unpublished information. This work was supported by the Polish Academy of Sciences within the project 09.7 .

\section{REFERENCES}

Apte, B. N., Bhavsar, P. N. \& Siddiqui, O. (1974). The regulation of arylsulphatase in Aspergillus nidulans. Journal of Molecular Biology 86, 637-648.

ARst, H. N. (1968). Genetic analysis of the first steps of sulphate metabolism in Aspergillus nidulans. Nature, London 219, 268-270.

Bessman, S. P., Kappanyi, Z. H. \& WapniR, R. A. (1967). A rapid method for homocysteine assay in physiological fluids. Analytical Biochemistry 18, 213219.

BRADFORD, M. M. (1976), A rapid and sensitive method for the quantitation of microgram quantities of protein utilizing the principle of protein-dye binding. Analytical Biochemistry 72, 248-254.

Dobeli, H. \& NuESCH, J. (1980). Regulatory properties of $O$-acetyl-L-serine sulfhydrylase of Cephalosporium acremonium. Evidence of an isoenzyme and its importance in cephalosporin C biosynthesis. Antimicrobial Agents and Chemotherapy 18, 111-117.

Guranowski, A. \& PASZewsKi, A. (1982). Metabolism of 5'-methylthioadenosine in Aspergillus nidulans. An alternative pathway for methionine synthesis via utilization of the nucleoside methylthiogroup. Biochimica et biophysica acta 717, 289-294.

Kredich, N. M. \& Tomkins, G. N. (1966). The enzyme synthesis of L-cysteine in $E$. coli and $S$. typhimurium. Journal of Biological Chemistry 241, 4955-4965.

LAEMMLI, U. K. (1970). Cleavage of structural proteins during the assembly of the head of bacteriophage $T_{4}$. Nature, London 227, 680-685.

Metzenberg, R. L. \& Parson, J. W. (1966). Altered repression of some enzymes of sulphur utilization in a temperature-conditional lethal mutant of Neurospora. Proceedings of the National Academy of Sciences of the United States of America 55, 629-635.
Morzycka, E. \& Paszewski, A. (1982). Cysteine and homocysteine synthesis in Saccharomycopsis lipolytica. Identification and characterization of two cysteine synthases. Acta biochimica polonica 29, 8193.

MorzycKa, E., SAWNOR-KorszyŃSKa, D., PASZEWSKI, A., GRABSKI, J. \& RACZYŃSKa-BOJANowsKA, K. (1976). Methionine overproduction by Saccharomycopsis lipolytica. Journal of Applied and Environmental Microbiology 32, 125-130.

Paszewski, A. \& Grabski, J. (1973). Studies on $\beta$ cystathionase and $O$-acetylhomoserine sulf hydrylase as the enzymes of alternative methionine biosynthetic pathways in Aspergillus nidulans. Acta biochimica polonica 20, 159-168.

PAszewski, A. \& Grabski, J. (1974). Regulation of Samino acids biosynthesis in Aspergillus nidulans: role of cysteine and/or homocysteine as regulatory effectors. Molecular and General Genetics 132, 307-320.

PaszewsKi, A. \& GrabsKI, J. (1975). Enzymatic lesion in methionine mutants of Aspergillus nidulans: role and regulation of an alternative pathway for cysteine and methionine synthesis. Journal of Bacteriology 124, 893-904.

Pieniążek, N. J., Bal, J., Balbin, E. \& Stępień, P. P. (1974). An Aspergillus nidulans mutant lacking serine transacetylase: evidence for two pathways of cysteine biosynthesis. Molecular and General Genetics 132, 363-366.

Pieniążek, N. J., Stępień, P. P. \& Paszewski, A. (1973a). An Aspergillus nidulans mutant lacking cystathionine $\beta$-synthase: identity of L-serine sulfhydrylase with cystathionine $\beta$-synthase and its distinctness from acetyl-L-serine sulfhydrylase. Biochimica et biophysica acta 297, 37-47.

PieniążeK, N. J., Kowalska, I. M. \& Stępień, P. P. 
$(1973 b)$. Deficiency in methionine adenosyltransferase resulting in limited repressibility of methionine biosynthetic enzymes in Aspergillus nidulans. Molecular and General Genetics 126, 367374.

Pontecorvo, G., Roper, J. A., Hemmonds, L. M., McDonald, K. D. \& Bufton, A. W. (1953). The genetics of Aspergillus nidulans. Advances in Genetics 5, 141-238.

Razzell, W. E. (1963). Phosphodiesterases. Methods in Enzymology 6, 236-258.

SIEGEL, L. M. (1965). A direct microdetermination for sulphide. Analytical Biochemistry 11, 126-132.

Siddiqui, O., APTE, B. N. \& Pitale, M. P. (1966).
Genetic regulation of aryl-sulphatase in Aspergillus nidulans. Cold Spring Harbor Symposia on Quantitative Biology 31, 381-382.

DE Vito, P. C. \& DReyfuss, J. (1964). Metabolic regulation of adenosine triphosphate sulphurylase in yeast. Journal of Bacteriology 88, 1341-1348.

WIEBERS, J. L. \& GARneR, Y. (1967). Acyl derivatives of homoserine as substrates for homocysteine synthesis in Neurospora crassa, yeast and Escherichia coli. Journal of Biological Chemistry 242, 5644-5649.

Yamagata, S., Takeshima, K. \& Naiki, N. (1975). $O$ Acetylserine and $O$-acetylhomoserine sulfhydrylase of yeast: studies with methionine auxotrophs. Journal of Biochemistry 77, 1029-1036. 